\title{
Lost decade 'undermining dentistry's pandemic recovery'
}

An historic collapse in dentists' earnings across the UK is jeopardising the long-term recovery of the service from the COVID19 pandemic, says the British Dental Association.

BDA analysis of new official earnings and expense level figures shows high street dentists in England NHS dental practices have seen taxable income fall by nearly $40 \%$ in real terms over the last decade. The story is replicated across the UK nations, with real terms falls in Wales, Scotland and Northern Ireland of well over a third since 2009.

The new 2019/20 figures capture the period just before the first lockdown. Above-inflation uplifts have remained the exception rather than the rule since the financial crash, with across-the-board cuts in pay in both cash and real terms. The historic driver of low morale in the sector remains the discredited target-based NHS dental contract imposed on the profession in 2006, which has proved incompatible with providing care during the pandemic.

Taxable income for all average selfemployed dentists in Northern Ireland fell from $£ 68,000$ in $18 / 19$ to $£ 65,100$ in $2019 / 20$. Associate dentists have seen their pay fall in real terms by $36 \%$ since $2008 / 9$, and by $43 \%$ for practice owners. While dentists across the UK have experienced sustained cuts to their real incomes, practitioners in Northern Ireland have seen their pay eroded by far the largest proportion.

Of particular concern says the BDA is that those dentists who are most committed to the Health Service have been hit the hardest. The largest dental group, representing associates where Health Service earnings account for at least $75 \%$ of their total gross earnings have the lowest average taxable income at $£ 49,700$.
This compares with an average taxable income of $£ 94,500$ for associates with $25 \%$ or less earnings from Health Service dentistry and a larger private income.

The stark fall in dentists' pay in Northern Ireland is being attributed to wholly inadequate fee uplifts, cuts in the form of removal of Health Service Commitment payments, and private work often effectively cross-subsidising HS activity. While the Northern Irish government has granted capital funding in the wake of the pandemic, dentists have historically relied on their incomes for all investment in improving equipment and facilities in HS practices.

Shawn Charlwood, Chair of the BDA's General Dental Practice Committee said: 'This lost decade on pay will inevitably undermine NHS dentistry's recovery.

'Government has taken the 'do more with less' mantra to the nth degree. Every penny of investment in this service comes from dentists' own pockets. This historic squeeze has left practices unable to deliver needed improvements in facilities, equipment, and training, even before the added costs of COVID-19 arrived.

'The pandemic has exposed the rotten foundations this service is built on, with failed systems and underinvestment leaving millions unable to secure the care they need.

'Dentists need to see this service as a place they'd chose to build a career. From discredited contracts to flat lining pay, no one should be penalised for working in the NHS.'

Richard Graham, chair of the BDA's NI

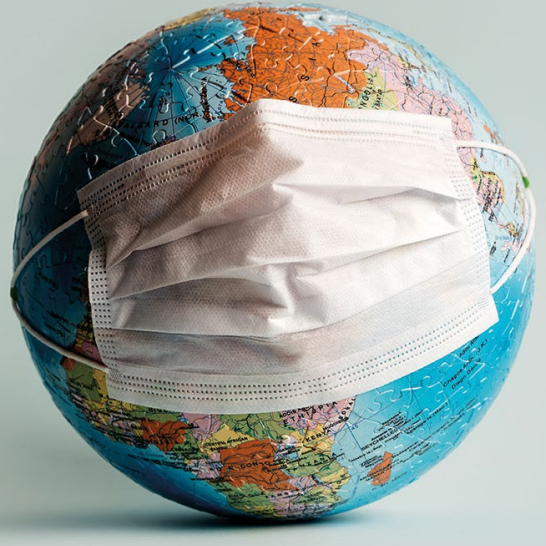

Dental Practice Committee added: 'When post-pandemic, patients across Northern Ireland are already struggling to access dental services, these figures should serve as a wake-up call.

'Before COVID-19 struck, Health Service dentistry had been run into the ground. Colleagues are facing the greatest oral health problems in the UK with their hands tied by a decades-old contract model that rewards failure, and chronic underfunding in wholly inadequate fees that no longer make any financial sense.

'We want to avoid a complete collapse of Health Service dentistry. For that to happen, we need a new contract model that works for both the general public and practitioners alike.

'For our patients' sake, the downward trajectory needs to be reversed before any more dentists conclude there is no future in the Health Service they have been so committed to. If Health Service dentistry is going to survive this pandemic, the time to give practitioners confidence it has a future is now.

\section{Forgotten Women Volunteer Dental Project: Register your interest}

Forgotten Women, a charity that provides aid to the world's most vulnerable women, are looking to recruit $4 / 5$ female dentists for a forthcoming project.

The project in Bangladesh will provide free dental work to those in need, travelling for 10 days across different villages, slums, and orphanages.

Due to ongoing uncertainty surrounding
COVID-19 there is no confirmed date as of yet, but the charity is hoping to complete this project in January.

To register your interest or for further information, contact Rhianna from

the Forgotten Women team on dorrianrhianna5@gmail.com.

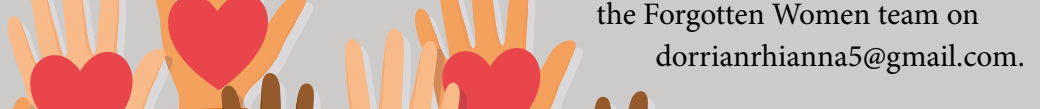

